Año LXXXII. urtea $279-2021$ Enero-abril Urtarrila-apirila

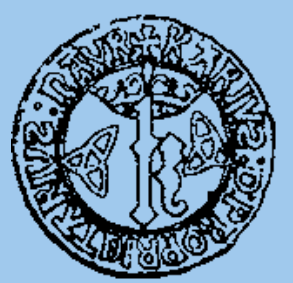

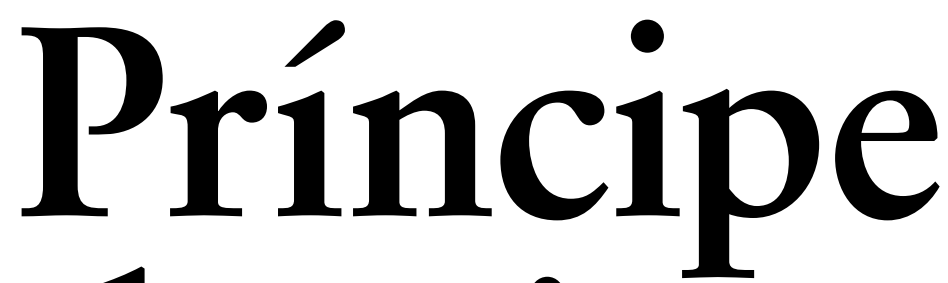

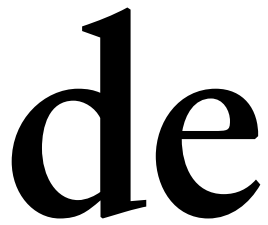

SEPARATA

Narrativa de autores navarros en castellano, año 2020

Mikel ZUZA VINIEGRA 


\section{Sumario / Aurkibidea}

\section{Príncipe de Viana}

Año LXXXII • n. ${ }^{\circ} 279$ - enero-abril de 2021

LXXXII. urtea $\cdot 279$. zk. 2021 ko urtarrila-apirila

\section{GUSTAV HENNINGSEN / MARISA REY-HENNINGSEN}

\section{Homenaje / Omenaldia}

Ignacio Panizo (coord./koord.)

Vol. II. lib.

\section{ESTUDIOS DE INVESTIGACIÓN EN HOMENAJE \\ A GUSTAV HENNINGSEN Y MARISA REY-HENNINGSEN / \\ IKERKETA LANAK, GUSTAV HENNINGSENEN \\ ETA MARISA REY-HENNINGSENEN OMENEZKOAK}

Entre impostores anda el juego en el Siglo de Oro. Dos vizcaínos ante la Inquisición y unos conversos toledanos próximos a Garibay

Un formulario de la Secretaría de Aragón del Consejo de la Inquisición (BC, ms. 2168)

Anna Gudayol

Las cartillas editadas en Estella e incautadas en Medellín por la Inquisición (1561)

Javier Itúrbide Díaz

El Tribunal de Navarra y sus funcionarios inquisitoriales:

algunas observaciones

Consuelo Juanto Jiménez

Goya investigado por la Inquisición: la censura de los Caprichos en 1804

$\mathrm{El}$ «Informe del inquisidor Avellaneda» sobre las complicidades brujeriles en los valles centrales y orientales del Pirineo navarro José M. Floristán Imízcoz, Jesús Moya Mangas 


\section{Sumario / Aurkibidea}

La Inquisición en Tudela durante los siglos XVI y XVII:

presencia e incidencia social

Iñigo Pérez Ochoa

La huella de la Inquisición en la Biblioteca de Navarra

Roberto San Martín Casi

Los memoriales como fuente para el estudio de la Inquisición

en el Tribunal de Navarra (1609-1621)

Bárbara Santiago Medina

De comisarios, confesores y vecinos: la proyección de la Inquisición

a finales del Antiguo Régimen

Marina Torres Arce

Los niños como víctimas y los niños como verdugos en la caza de brujas:

Navarra, siglo XVI

Jesús M. Usunáriz

Volver a las relaciones de causas. El ejemplo de los berberiscos

del reino de Granada

Bernard Vincent

\section{LOS TRABAJOS Y LOS DÍAS DEL AÑO 2020 / 2020ko LANAK ETA EGUNAK}

Tesis doctorales sobre temática navarra de ciencias humanas, sociales y jurídicas, leídas en 2020

(Según la Base de datos Teseo del Ministerio de Educación)

Narrativa de autores navarros en castellano, año 2020

Mikel Zuza Viniegra

Euskarazko literaturak 2020an zer?

Ángel Erro Jiménez

Donación del fondo bibliográfico y documental Gustav Henningsen y Marisa

Rey a la Universidad Pública de Navarra

Iñaki Montoya Ortigosa

Formación en Archivística y Gestión Documental en la Universidad de Navarra

Yolanda Cagigas Ocejo

6 Príncipe de Viana (PV), 279, urtarrila-apirila, 2021

ISSN: 0032-8472 | ISSN-e: 2530-5824 | ISSN-L: 0032-8472

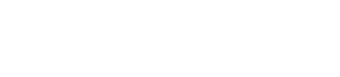




\section{Sumario / Aurkibidea}

Apuntes sobre etnografía, folclore y cultura tradicional David Mariezkurrena Iturmendi

El alivio y reparo. La forma audiovisual

Marga Gutiérrez Díez

Proceso de decantación. Exponer en 2020

Mireya Martín Larumbe

Exposición «Maleficium. Navarra y la caza de brujas. Siglos XIV-XVII»

(Archivo Real y General de Navarra, julio-diciembre, 2020)

Jesús M. Usunáriz

Carlos Cánovas

Alicia Ezker Calvo

Discurso Premio Príncipe de Viana 2020

Carlos Cánovas Ciaurriz

Currículums

Analytic Summary

Normas para la presentación de originales / Idazlanak aurkezteko arauak /

Rules for the submission of originals 


\title{
Narrativa de autores navarros en castellano, año 2020
}

\author{
Mikel Zuza Viniegra \\ Red de Bibliotecas de Navarra / Nafarroako Liburutegien Sarea \\ Mikel.zuza.viniegra@navarra.es
}

DOI: https://doi.org/10.35462/pv.279.14

Entre la narrativa de autores y autoras navarros que se publicó en el año 2020 pueden destacarse los siguientes títulos:

Sergio Amadoz editó en Libros del KO Aquí no se rinde ni Dios, gavilla de recuerdos osasunistas tejida por el autor en el año del centenario del club.

Txaro Begué escribió Nada es diferente después de todo, novela histórica protagonizada por mujeres, que transcurre en la época de la llegada de los romanos a territorio vascón.

Daniel Bidaurreta publicó El director: (historia de una conspiración), novela basada en la figura del general Mola y su papel en la sublevación contra el gobierno legítimo en 1936.

Iñaki Echarte editó en Tres Hermanas Ninguna ciudad es eterna, libro de relatos centrados en la ciudad de Venecia.

Aingeru Epaltza publicó en Txertoa Mal de altura, la traducción al castellano de sus relatos, donde las relaciones humanas tienen como trasfondo la afición al monte.

Pascual García Arano editó en Eunate Delicuenciario, novela policiaca en la que el mundo carcelario juega un importante papel.

Pello Guerra escribió para Astero Muerte a la reina de Navarra, novela histórica protagonizada por la reina Juana III de Albret y la conspiración para acabar con su vida. 
Jorge Gutiérrez editó en Maluma Un viaje prodigioso: guerra microscópica I, una novela que descubre cómo funciona el cuerpo humano en forma de fantasía épica.

Manuel Horno publicó en Bala Perdida Las haraganas, novela sobre tres hermanas solteras que viven con su madre sin atreverse a romper las barreras morales que las rodean.

Patxi Irurzun escribió para Pamiela Tratado de hortografía: una novela sobre el Rock Radikal Vasco, protagonizada por un viejo rockero que tuvo su momento de gloria en los 80 .

Isabel Lizarraga escribió para Eunate iQue venga «la Julia»!: Julia Álvarez Resano, la navarra que enardeció multitudes, novela protagonizada por Julia Álvarez, la maestra que llegó a ser la primera mujer nombrada gobernadora civil en España.

Ignacio Lloret editó en Eunate Una ventana a la oscuridad, novela de Ignacio que aborda temas como los límites entre realidad y ficción o los riesgos de lo imaginario.

Santi Lorente publicó Los cuentos del confinamiento: pasión por vivir, recopilación de los relatos de diferentes géneros que fue escribiendo durante los meses de encierro pandémico.

Héctor Martín publicó en Titanium Buen ojo, novela negra en la que su protagonista, la detective Claudia, busca resolver un caso que empuje su carrera policial.

Carlos Ollo escribió para Erein Mortaja de barro, tercera entrega de la serie de novelas policiacas protagonizadas por el inspector Villatuerta.

Amaia Oloriz editó La sombra que habita en tus ojos, novela que transcurre en el valle del Roncal, y que se inicia con la misteriosa desaparición de Ascensión Artuch, vecina muy estimada.

Begoña Pro publicó en Txertoa El álferez del estandarte real, novela histórica que narra la vida del caballero Martín Ximénez de Aibar en la Navarra de fines del siglo XIII.

Miguel Sánchez-Ostiz, escribió para Pamiela Breves del desconcierto: soliloqueos, apostillas, enojos y boteprontos 2018-2020, nuevo breviario en el que el autor, a través de textos breves anota sus reflexiones sobre los tiempos que vivimos.

Idoia Saralegui editó El laberinto de Celia, novela romántica que constituye la segunda parte de la anterior obra de la autora: La proposición de Carola.

Juan Torres Zalba publicó en Esfera de los Libros El primer senador de Roma: Carthago delenda est, novela histórica que nos traslada a la Roma del siglo II antes de Cristo. 
Mikel Zuza editó en Pamiela Sin cobertura, recopilación de artículos sobre cultura y patrimonio histórico.

Respecto a la poesía navarra publicada en 2020, pueden citarse las siguientes obras:

Ramón Eder publicó en Renacimiento Cafés de techos altos, nuevo libro de aforismos del autor.

Teresa Ramos escribió Cierta belleza, recopilación de poemas que invita a indagar en lo íntimo y en lo social.

Alfonso Pascal Ros editó en Celya 130 pulsaciones: (antología poética 1985-2020), recogiendo una muestra de la veintena de poemarios que ha publicado durante los últimos treinta y cinco años.

Regina Salcedo escribió para Huerga \& Fierro Lo que dejamos fuera, poemario donde la fotografía y la forma de mirarla tiene su propia singularidad.

Verbo Divino publicó la colección de poemas religiosos escritos por Víctor Urrutia titulada Camino de Emaús. 
0 